\title{
Fatigue in Post-Polio Syndrome
}

\section{Monalisa Pereira Motta ${ }^{1}, *$ Abrahão Augusto Juveniano Quadros $^{1,2}$, Letícia Simões Ferreira ${ }^{1}$ and Acary Souza Bulle Oliveira $^{1}$}

\begin{abstract}
${ }^{1}$ Federal University of São Paulo (UNIFESP). Division of Neuromuscular Disorders. Department of Neurology and Neurosurgery. Rua Pedro de Toledo, 650. Vila Clementino. São Paulo-SP, Brazil (CEP 04039-002). *Email: mona_motta@yahoo.com.br.

${ }^{2}$ Neurologic Rehabilitation Service. Policlínica. Centro Universitário Adventista de São Paulo (UNASP). Estrada de Itapecerica, 5859. São Paulo-SP, Brazil (CEP 05858-001).
\end{abstract}

\begin{abstract}
Post-Polio Syndrome (PPS) is characterized by the appearance of new muscular symptoms or worsening of previous residual symptoms, several years after the acute polio. The most common symptoms include a trial of fatigue, deterioration in muscle strength and pain. Fatigue is one of the most frequent complaints of PPS and the majority of patients identify fatigue as their most troubling symptom. The aetiology of the symptom arouses great interest, mainly due to its multifactorial character, and can be divided into two components: peripheral (muscular) fatigue and central (general) or simultaneously-occurring fatigue. Considering the importance of the symptom and the limitations that can cause in PPS patients, it is important to consider a series of variables, so that it can be better understood, thus providing a more effective and specific treatment.
\end{abstract}

Keywords: Post-Poliomyelitis Syndrome; Neuromuscular disorders; Fatigue; Central fatigue; Muscular fatigue.
Received

December 24, 2018

Accepted

February 23, 2019

Released

April 30, 2019

Full Text Article

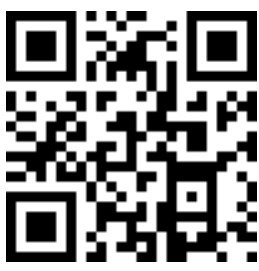

ORCID
0000-0003-2071-1216
Monalisa Pereira
Motta
0000-0001-8197-5915
Abrahão Augusto
Juveniano Quadros
0000-0001-6210-8445
Letícia C Simões
Ferreira
0000-0002-6986-4937
Acary Souza Bulle
Oliveira 


\section{Introduction}

Post-Poliomyelitis Syndrome (PPS) is characterized by a range of lateonset neuromuscular symptoms such as joint and muscular pain, new or increased muscle weakness and abnormal fatigability as key symptoms (Rowland et al., 2000; Motta et al., 2018).

Among the symptoms of PPS, fatigue is one of the most frequent and is probably the main symptom. It is the most incapacitating, most debilitating and causes the greatest interference in the everyday activities of the patients. Most of the time, it manifests itself in the afternoon, with improvement after a period of rest, often preceding the introduction of new muscle weakness. Although occurring in about $60 \%-89 \%$ of individuals with PPS, it is one of the least studied symptoms (Bruno et al., 1994, 1995; Trojan et al., 1994, 2005).

Conde et al. (2009) pointed out that fatigue in patients with PPS is not related to a period of the day, but to the type of activity performed. However, Viana et al. (2013) reported that fatigue is more intense in the afternoon for patients with poliomyelitis sequelae and worsens progressively in patients with PPS.

As a symptom, fatigue is difficult to define and can be characterized as a complex, multicausal, multidimensional and subjective phenomenon involving temporal, sensory, affective, biomechanical, cognitive, physical, psychological and severity domains (Mota et al., 2005; Chalder et al., 1993). It usually occurs as a non-specific complaint with numerous possible etiologies: systemic metabolic diseases (hypothyroidism, hyperthyroidism, diabetes mellitus), cancer/chemotherapy, anemia, cardiac conditions (myocardiopathy, coronary artery disease, arrhythmias), chronic infection, kidney disease, lupus systemic erythematosus, liver disease; respiratory dysfunction (chronic alveolar hypoventilation, hypoxemia), sleep disorder (apnea, periodic movements of the legs); mood disorders (depression, anxiety/ stress) (Oliveira and Quadros, 2008). For any potential PPS patient, it is important that the characteristics, time of fatigue manifestation and the activities that produce it are recorded. This information helps determine the cause of the problem. Fatigue that manifests soon after waking up usually reflects sleep changes that can be caused by several factors. Fatigue that continues throughout the day is not typical of PPS and may indicate other conditions, such as chronic fatigue syndrome (Oliveira and Quadros, 2008).

The etiology of the symptom arouses great interest, mainly due to its multifactorial character, and can be divided into two components: peripheral (muscle) fatigue and central (general) fatigue (Bertuzzi et al., 2004). To understand the context of fatigue, it is important to adopt an integrated approach. It is also necessary to identify where the fatigue originates, that is, the central nervous system, the peripheral nervous system or both (Östlund et al., 2011).

\section{Central fatigue (General)}

Central fatigue occurs in one or several levels of the nerve structures that intervene in physical activity. From there, it can cause a change in transmission from the central nervous system, or in the recruitment of motor axons. It is usually associated with prolonged low-intensity efforts, as well as high intensity efforts (Santos et al., 2003).

The central fatigue mechanism relates to the formulation of motor patterns, as well as transmission of the same throughout the cerebral cortex, cerebellum, and synaptic junctions to specific efferent nerves within the spinal cord. This fatigue may come from one or more nerve structures involved in the production or maintenance of muscle contraction control (Santos et al., 2003). It is characterized by a failure in the 
conduction of the nerve impulse, promoting a reduction in the number of active motor units and a decrease in the frequency of firing of the motoneurons, part of which is related to the neurotransmitters (Ascensão et al., 2003).

It can also occur at the supraspinal level through afferent inhibition from neuromuscular spindles, nerve endings, the depression of motor neuron excitability and synapse failures. At this level, there is purported to be a mechanism related to the alteration in the neurotransmitters of the synapses between the microneurons of the Renshaw circuit and the alpha neurons. Acetylcholine is one of the neurotransmitters that may be related to central fatigue. Choline depletion, the main precursor of acetylcholine, may contribute to the metabolism of central fatigue. A restriction in choline consumption may decrease the rate of impulse transmission in the skeletal muscles (Santos et al., 2003).

Central fatigue can be defined as a sudden feeling of generalized exhaustion, which is aggravated by physical activity, described as being a fatigue similar to that of the flu. This sudden onset of symptoms includes intense fatigue, weakness, fluctuation between hot and cold, and sweating. It usually occurs in the late afternoon or early evening and is typically caused by the accumulation of small activities that do not require much effort or cause visible sequelae (Trojan and Cashman, 2005; Berlly et al., 1991). The cause of general fatigue in PPS is unknown and practically unstudied. Possible causes include increased weakness and muscle fatigue, dysfunctional activation of reticular formation, chronic pain, respiratory dysfunction, cardiorespiratory disconnection (reduced function due to low activity), depression, "type A" behavior, sleep disturbances, muscle abnormalities, fibromyalgia and reduced dopamine secretion (Trojan et al., 1994).
The symptoms of central fatigue are: disturbances of concentration, memory, attention and staying awake. This is a normal experience in healthy individuals after mental effort, or lack of sleep. Mental fatigue affects cognitive functions such as planning and inhibition and is related to mental sustainability and ability to concentrate but does not affect more automatic abilities. Sleep disorders are reported as a common problem in patients with PPS (Östlund et al., 2011).

Based on these clinical manifestations, it is suggested that central fatigue in PPS cannot be explained merely by an induction of poliovirus to neurons within the anterior horn of the spinal cord. This gives rise to the hypothesis of polioviral activity in some specific areas of the brain responsible for cortical activation, an intriguing cause (Bruno et al., 1995). This has been confirmed in postmortem studies for more than 50 years, which have demonstrated poliovirus lesional activity in cerebral areas such as the hypothalamus, thalamus, caudate nucleus, putamen, globus pallidus, reticular formation and, particularly, the substantia nigra, even in clinically mild cases (Bodian, 1949; Bruno et al., 1995). Clinical reports written during polio epidemics corroborate the pathological evidence of poliovirus injury to the ascending reticular system, as prolonged drowsiness, lethargy and even coma have been described as sequelae of acute poliovirus infection (Bruno et al., 1995). In a study of 22 patients with PPS, hyperintense signals were found in conventional magnetic resonance imaging of the central brain structures in $55 \%$ of patients with moderate or severe fatigue, but none with mild or no fatigue (Bruno et al., 1995).

Prior to these studies, it was believed that the fatigue experienced by patients with PPS was only related to muscular aspects. As this is a rather controversial subject, since then, several 
studies have been performed to truly prove the presence of central fatigue. Schanke and Stanghelle (2001) and Trojan and Cashman (2005) reported that fatigue in PPS is more predominantly physical than central. In the study by Bruno et al. (1994), it was shown that PPS patients presented cognitive difficulties, including problems with attention and speed in the processing of information.

In the study by Östlund et al. (2008), most of the perception of vitality in PPS was physiological, i.e., fatigue in patients with PPS is mostly experienced as physical. Östlund et al. (2011) divided their sample of 143 patients into three groups: fatigued, non-fatigued and intermediate; in order to better understand the central and peripheral aspects of fatigue. They noted that the fatigued group had significantly more physical and mental fatigue as compared to the intermediate and non-fatigued groups. However, in the fatigued group, mental fatigue was of relatively greater importance than physical fatigue for vitality. In the non-fatigued and intermediate groups, the pattern was reversed. This suggests that the fatigued group is not only descriptively different, but also that the mechanisms behind the variation in vitality are different.

A study of fatigue involving 89 patients found a high degree of fatigue in three of the five MIF-20 sub-scales. Most of the individuals reported physical fatigue (90\%), general fatigue (89\%) and reduced activity (84\%). Half of the sample reported mental fatigue and reduced motivation (Silva et al., 2016). A transverse study related several variables to the types of fatigue. A considerable proportion of general, physical and mental fatigue in PPS was explained by potentially modifiable variables. Psychosocial variables (stress, depression, and self-efficacy) contributed significantly to general and mental fatigue, while pain and physical activity contributed to physical fatigue. It has been suggested that better management of these predictors will provide a reduction in fatigue (Trojan et al., 2009).

It is important to differentiate between physical fatigue, and decreased endurance associated with new weakness and central fatigue. Between $70 \%$ and $90 \%$ of patients with paralytic polio sequelae report fatigue as responsible for memory, concentration and attention problems. Moderate to intense fatigue hindering their function is reported by $77 \%$ of the patients (Bruno et al., 1995, 1194; Quadros, 2005). The differentiation of Chronic Fatigue Syndrome (CFS) from the fatigue that occurs in PPS is very important, since both have similar clinical signs, such as: disturbance of concentration, sleep disturbance and muscle weakness, among others, besides having a common viral etiology. However, CFS is only defined when fatigue persists for more than 6 months and is accompanied by neuromuscular and neuropsychological symptoms. Its etiology is still unknown; there are etiological hypotheses that CFS would be triggered by a variety of factors, including viral exposure to one of the following agents: Epstein-Barr virus, human herpesvirus 6, group B coxsackieviruses, hepatitis $C$ virus and human herpesvirus 7 (Ablashi, 1994).

\section{Peripheral fatigue (muscular)}

The inability of skeletal muscle to generate high levels of strength, or maintain these levels for a certain time, is known as peripheral or muscular fatigue (Grimby et al., 1989; Trojan and Cashman, 2005).

Peripheral fatigue presents failure or limitation of one or more components of the motor unit (motor neurons, peripheral nerves, neuromuscular connections or muscle fibers). It is characterized by the deterioration of the muscle's biochemical and contractile processes, with depletion of the energy substrates and the accumulation of metabolites (Ascensão et al., 2003). Whether located in plasma 
membranes, sarcoplasmic reticulum or myofibrils, the availability of some energy substrates, such as creatine phosphate, blood glucose and glycogen for the synthesis of adenosine triphosphate (ATP) and creatine phosphate (while a substrate for specific ATPases) have been discussed as predisposing factors of peripheral muscle fatigue (Ascensão et al., 2003; Bertuzzi et al., 2004).

As such, peripheral fatigue is based on associations of energy substrate depletion and metabolite production, events that act upon the release of calcium, and on the intracellular processes that influence the functioning of the peripheral nervous system (Ascensão et al., 2003; Bertuzzi et al., 2004). These factors would lead to less force production and slower recovery, which would be caused by problems in the muscle's electrical activation and defects in the excitationcontraction coupling or in the contractile process. However, due to the complexity of these events, muscle fatigue can originate from one or all of the physiological systems involved in muscle action, from the central nervous system to the peripheral nervous system (Bertuzzi et al., 2004). It may occur at the neuromuscular junction and cell membrane (excitation), in the calcium release mechanism (activation) or in the sliding readers (contractile processes) (Sunnerhagen and Grimby, 2001).

The specificity of the muscle fibers recruited during a given physical performance may represent an important relation to the origin of the fatigue. The fast contraction fibers present a more developed sarcoplasmic reticulum than the slow contraction fibers, facilitating the release of calcium inside the muscle cell. In contrast, slow contraction fibers have a more efficient oxidative system for energy production (Santos et al., 2003). Grimby et al. (1989) reported a transformation of type II muscle fibers into type I fibers, causing patients with PPS to have a predominance of type I muscle fibers. A Brazilian study analyzed muscle biopsies from this population, confirming the predominance of type I muscle fibers (Oliveira and Quadros, 2008). This adaptation is believed to occur most likely as a result of excessive use of reduced muscle mass. However, it was expected that the predominance of slowtwitch fibers (type I) would increase the muscle oxidative potential. In turn, this would increase resistance to fatigue, as these type I normal ones have higher levels of oxidative enzymes than type II (Halstead and Rossi, 1987).

Other adaptations that may alter the fatigue resistance of muscle fibers have also been described. It has been observed that the mean cross-sectional area of the muscle fiber is about twice as high in patients with PPS, when compared to healthy individuals (Grimby et al., 1989); it is observed that, despite this hypertrophy, the capillary supply is reduced in relation to the area of the muscular fiber. This can impair the diffusion capacity, causing a substrate shortage during muscular work (Borg and Henriksson, 1991). It is unclear whether the combination of these adaptations will increase or reduce the fatigue resistance of muscle fibers in PPS patients (Thomas and Zijdewind, 2006).

Another hypothesis is that peripheral fatigue results from a neuromuscular transmission defect, an increase in transmission time at the neuromuscular junction (jitter) and blockade. It is unclear, however, this may reflect the ineffective reinnervation of giant motor units, continuous remodeling of the same, and a metabolic abnormalities in motor neurons affected by poliovirus, which prevents them from providing normal innervation to all reinnervated muscle fibers (Wiechers, 1988). The causes of peripheral fatigue involve dysfunction of the neuromuscular junction due to metabolic exhaustion of the motor unit; disproportion of fiber types, and myopathy due to overuse. Its symptoms 
include decreased muscular endurance and muscle fatigue (Thorsteinsson, 1997). Muscle exercise causes rapid consumption of ATP, and energy deficiency is an important factor in fatigue. As such, exogenous dietary substances that can lead to the production of ATP are considered as (potential) candidates for anti-fatigue materials (Sugino et al., 2007).

Quadros (2005) suggested that fatigue may be related to physical factors and emotional stress due to the introduction of new weakness, breathing problems during sleep and gradual loss of functionality. This was because he found a significant difference in fatigue found in patients with late poliomyelitis sequelae $(34.2 \%)$ and in patients with PPS (77.5\%).

Despite being more frequent and having a greater relationship with the fatigue mentioned by the patients with PPS, the knowledge on peripheral fatigue is still limited. It may result from motorunit reorganization and the altered activity and function pattern of the remaining muscle fibers that occurred during poliomyelitis recovery and secondary decline (Thomas and Zijdewind, 2006). These factors may be important for the development of muscle fatigue, especially post-exercise fatigue, myalgia, and transient muscle strength, which are common symptoms in patients affected by poliomyelitis (Grimby and Einarsson, 1989).

\section{Low frequency fatigue}

An interesting, but inexplicable finding is that the perception of fatigue remains in poliomyelitis victims for days after a tiring exercise, though without reduction in maximal voluntary contraction (Agre et al., 1989). One possible explanation is low-frequency fatigue, characterized by a substantial reduction in tension at low stimulation frequencies (Edwards, 1981). Delayed recovery is characteristic of lowfrequency fatigue, with it taking up to 1 day to restore full energy, thus contributing considerably to the feeling of weakness in muscle groups after intense exercise (Sunnerhagen and Grimby, 2001).

Decreased muscular endurance and increased peripheral fatigue are common and may precede weakness. As a first subtle sign, an increase in recovery time may be noticed after an activity, and a deterioration of muscle resistance may occur slowly (Östlund et al., 2005).

\section{Treatment}

Even today, its treatment is based on non-pharmacological interventions, lifestyle changes, physical therapy, exercise programs and the prevention of secondary complications through orthoses and locomotion aids. Physical activity must be carefully performed, with a balance between activity and rest, so that the remaining neurons do not become overloaded and it does not lead them to atrophy due to disuse. Pharmacological options with proven benefits, and few adverse effects, were yet to be discovered as of 2017 .

More recently, a randomized clinical trial evaluated the action of 330 $\mathrm{mg}$ of L-carnitine in conjunction with 270 $\mathrm{mg}$ of piracetam (twice a day) in the treatment of fatigue and muscle weakness in 94 patients with PPS. The patients were evaluated over 180 days. Force was evaluated using the Medical Research Council Manual Muscular Test instrument. Fatigue was evaluated using the Severity and Fatigue Scale and Piper's Revised Fatigue Scale. The study found improvement in fatigue and muscle strength, as compared with a placebo, and a decrease in muscle strength in the patients who took the medication. The association of these two drugs has been shown to be effective in managing fatigue and muscle weakness in this population (Motta, 2017). 


\section{Conclusion}

Whether PPS fatigue is central or peripheral, it is important to keep in mind that, for many patients, this is the most disabling symptom and the one that brings about greater functional impairment. As such, patients should be advised on the practice of appropriate and supervised physical exercises, changes in lifestyle and energy saving strategies in order to reduce excessive metabolic load, thus providing an improvement in the symptom.

\section{Conflicts of interest}

Authors declare that they have no conflict of interests.

\section{References}

Ablashi, D. V. Viral studies of chronic fatigue syndrome. Clinical Infectious Diseases, v. 18, Suppl. 1, p. S130-S133, 1994.

Agre, J. C.; Rodriquez, A. A.; Sperling, K. B. Symptoms and clinical impressions of patients seen in a post-polio clinic. Archives of Physical Medicine and Rehabilitation, v. 70, No. 5, p. 367-370, 1989.

Ascensão, A.; Magalhaes, J.; Oliveira, J.; Duarte, J.; Soares, J. Fisiologia da fadiga muscular. Delimitação conceptual, modelos de estudo e mecanismos de fadiga de origem central e periférica. Revista Portuguesa de Ciências do Desporto, v. 3, No. 1, p. 108-143, 2003.

Berlly, M. C.; Strauser, W. W.; Hall, K. M. Fatigue in Postpolio Syndrome. Archives of Physical Medicine and Rehabilitation, v. 72, p. 115-118, 1991.

Bertuzzi, R. C. M.; Franchini, E.; Kiss, M. A. P. D. Fadiga muscular aguda: uma breve revisão dos sistemas fisiológicos e suas possíveis relações. Motriz, v. 10, No. 1, p. 45-54, 2004.

Bodian, D. Histopathologic basis of clinical findings in poliomyelitis. The American Journal of Medice, v. 6, no. 5, p. 563-578, 1949. https://doi.org/10.1016/0002-9343 (49)90130-8
Borg, K.; Henriksson, J. Prior poliomyelitisreduced capillary supply and metabolic enzyme content in hypertrophic slow-twitch (type I) muscle fibres. Journal of Neurology, Neurosurgery \& Psychiatry, v. 54, No. 3, p. 236-240, 1991.

Bruno, R. L.; Cohen, J. M.; Galski, T.; Frick, N. $M$. The neuroanatomy of post-polio fatigue. Archives of Physical Medicine and Rehabilitation, v. 75, p. 498-503, 1994.

Bruno, R. L.; Sapolsky, R.; Zimmerman, J. R.; Frick, N. M. Pathophysiology of a central cause of post-polio fatigue. Annals of New York Academy of Science, v. 753, p. 257275, 1995. https://doi.org/10.1111/j.17496632.1995.tb27552.x

Chalder, T.; Berelowitz, G.; Pawlikowska, T.; Watts, L.; Wessely, S.; Wright, D.; Wallace, E. P. Development of a fatigue scale. Journal of Phychomatic Research, v. 37, no. 2, p. 147153, 1993. https://doi.org/10.1016/00223999(93)90081-P

Conde, M. T. R. P.; Oliveira, A. S. B.; Quadros, A. A. J.; Moreira, G. A.; Silva, H. C. A.; Pereira, R. D. B.; Silva, T. M.; Tufik, S.; Waldman, E. A. Post-Polio Syndrome: Epidemiologic and prognostic aspects in Brazil. Acta Neurologica Scandinavica, v. 120, p. 191197, 2009. https://doi.org/10.1111/j.16000404.2008.01142.x

Edwards, R. Human muscle function and fatigue: Physiological mechanisms. In: Porter, R.; Whelan, J. Human muscle fatigue: Physiological mechanisms. London: Pitman Medical, 1981. (Ciba Foundation Symposium, 82). p. 1-18.

Grimby, G.; Einarsson, G. Muscle morphology with special reference to muscle strength in post-polio subjects. Birth Defects Original Article Series, v. 23, No. 4, p. 265-274, 1987.

Grimby, G.; Einarsson, G.; Hedberg, M.; Aniansson, A. Muscle adaptive changes in post-polio subjects. Scandinavian Journal of Rehabilitation Medicine, v. 21, No. 1, p. 1926, 1989.

Halstead, L. S.; Rossi, C. D. New problems in old polio patients: results of a survey of 539 polio survivors. Orthopedics, v. 8, p. 845850, 1985. 
Halstead, L. S.; Rossi, C. D. Post-polio syndrome: clinical experience with 132 consecutive outpatients. Defects Original Article Series, v. 23, p. 13-26, 1987.

Mota, D. D. C. F.; Cruz, D. A. L. M.; Pimenta, C. A. M. Fadiga: uma análise do conceito. Acta Paulista de Enfermagem, v. 18, No. 3, p. 285-293, 2005. https://doi.org/10.1590/ S0103-21002005000300009

Motta, M. P. Efeito terapêutico do uso da Lcarnitina+piracetam na fadiga e na força muscular de pacientes com Síndrome PósPoliomielite (SPP): estudo clínico randomizado, duplo-cego, controlado com placebo. São Paulo: Universidade Federal de São Paulo, Escola Paulista de Medicina, 2017. (Master thesis).

Motta, M. P.; Quadros, A. A. J.; Brito, M. C.; Oliveira, A.S. B. Post-Polio Syndrome. Brazilian Journal of Biological Sciences, $\begin{array}{lll}\text { v. } 5, \quad \text { No. } 11, \quad \text { p. } 631-639, & 2018 .\end{array}$ https://doi.org/10.21472/bjbs.051102

Oliveira, A. S. B.; Quadros, A. A. J. Síndrome Pós-Poliomielite: orientações para profissionais de saúde. São Paulo: SES/SP, 2008. (Versão para Internet). Available from: <http://www.saude.sp.gov.br/resources/ses /perfil/profissional-da-saude/homepage// sindrome_pos_poliomielite_pdf $>$. Accessed on: Apr. 23, 2018.

Östlund, G.; Wahlin, A.; Sunnerhagen, K. S.; Borg, K. Post-Polio Syndrome: Fatigued patients a specific subgroup? Journal of Rehabilitation Medicine, v. 43, No.1, p.39-45, 2011. https://doi.org/10.2340/ 16501977-0634

Östlund, G.; Borg, K.; Wahlin, A. Cognitive functioning in post-polio patients with and without general fatigue. Journal of Rehabilitation Medicine, v. 37, No. 3, p. 147-151, 2005. https://doi.org/10.1080/ 16501970410024172

Östlund, G.; Wahlin, A.; Sunnerhagen, K. S.; Borg, K. Vitality among Swedish patients with post-polio: a physiological phenomenon. Journal of Rehabilitation Medicine, v. 40, No. 9, p. 709-714, 2008. https://doi.org/ $10.2340 / 16501977-0253$

Quadros, A. A. J.; Conde, M. T. R. P.; Marin, L. F.; Silva, H. C. A.; Mesquita e Silva, T.; Paula, M. B. E.; Pereira, R. D. B.; Ramos, P. E.; Abe, G.; Oliveira, A. S. B. Frequency and clinical manifestations of Post-Poliomyelitis
Syndrome in a Brazilian tertiary care center. Arquivos de Neuro-Psiquiatria, v. 70, no. 8, p. 571-573, 2012. https://doi.org/10.1590/ S0004-282X2012000800002

Rowland, L. P.; Bach, J. R.; Borg, K.; Cashman, N. R.; Dalakas, M. C.; Dean, E.; Halstead, L. S.; Headley, J. L.; John, T. J.; Johnston, R. B.; Olkin, R.; Perlman, S. L.; Trojan, D. A.; Vickrey, B. G.; Wendling, W.W. March of Dimes International Conference on Post-Polio Syndrome: Identifying best practices in diagnosis \& care. White Plains, NY: March of Dime, 2000. Available from: <https://www. polioplace.org/sites/default/files/files/MODIdentifying.pdf $>$. Accessed on: Apr. 23, 2018.

Santos, M. G.; Dezan, V. H.; Sarraf, T. A. Bases metabólicas da fadiga muscular aguda. Revista Brasileira de Ciência e Movimento, v. 11, No. 1, p. 7-12, 2003.

Schanke, A.-K.; Stanghelle, J. K. Fatigue in polio survivors. Spinal Cord, v. 39, p, 243251, 2001. https://doi.org/10.1038/sj.sc. 3101147

Silva, S. T.; Sunnerhagen, K. S.; Willén, C.; Hammar, O. The extent of using mobility assistive devices can partly explain fatigue among persons with late effects of polio: A retrospective registry study in Sweden. BMC Neurology, 16:230, 2016. https://doi.org/ 10.1186/s12883-016-0753-6

Sugino, T.; Aoyagi, S.; Shirai, T; Kajimoto, Y.; Kajimoto, 0. Effects of citric scid and lCarnitine on physical fatigue. Journal of Clinical Biochemestry and Nutrition, v. 41, No. 3, p. 224-230, 2007. https://doi.org/ 10.3164/jcbn.2007032

Sunnerhagen, K. S.; Grimby, G. Muscular effects in late polio. Acta Physiologica, v. 171 , p. $335-340,2001$. https://doi.org/ 10.1046/j.1365-201x.2001.00836.x

Thomas, C. K.; Zijdewind, I. Fatigue of muscles weakened by death of motoneurons. Muscle \& Nerve, v. 33, no. 1, p. 21-41, 2006. https://doi.org/10.1002/mus.20400

Thorsteinsson, G. Management of Postpolio Syndrome. Mayo Clinic Proceedings, v. 72, No. 7, p. 627-638, 1997. https://doi.org/ 10.1016/S0025-6196(11)63568-4

Trojan, D. A.; Arnold, D. L.; Shapiro, S.; Bar-Or, A.; Robinson, A.; Le Cruguel, J. P.; Narayanan, S.; Tartaglia, M. C.; Caramanos, Z.; Costa, D. Fatigue in Post-Poliomyelitis Syndrome: 
Association with disease-related, behavioral, and psychosocial factors. PM\&R, v. 1, No. 5, p. 442-449, 2009. https://doi.org/10.1016/ j.pmrj.2009.03.003

Trojan, D. A.; Cashman, N. R. PostPoliomyelitis Syndrome. Muscle \& Nerve, v. 31, No. 1, p. 6-19, 2005. https://doi.org/ 10.1002/mus.20259

Trojan, D. A.; Cashman, N. R.; Shapiro, S.; Tansey, C. M.; Esdaile, J. M. Predictive factors for Post-Poliomyelitis Syndrome. Archives of Physical Medicine and Rehabilitation, v. 75, No. 7, p. 770-777, 1994.

Viana, C. F.; Pradella-Hallinan, M.; Quadros, A. A. J.; Marin, L. F.; Oliveira, A. S. B. Circadian variation of fatigue in both patients with paralytic poliomyelitis and post-polio syndrome. Arquivos de Neuro-Psiquiatria, $\begin{array}{lll}\text { v. 71, } & \text { No. } 7, \quad \text { p. } 442-445, & 2013 .\end{array}$ https://doi.org/10.1590/0004-282X2013 0059

Wiechers, D. 0. New concepts of the reinnervated motor unit revealed by vaccineassociated poliomyelitis. Muscle \& Nerve, v. 11, No. $4, \quad$ p. 356-364, 1988. https://doi.org/10.1002/mus.880110412 